Department of Human Medicine, University PO Box 19063, Tygerberg 7505, South Africa J J Grobbelaar $\mathrm{G}$ de Jong C J J Oosthuizen M J Kotze

Department of Ophthalmology, Faculty of Medicine, University of Stellenbosch, Tygerberg, South Africa A Ziskind

Correspondence to: Dr Kotze.

Received 27 September 1995

Revised version accepted for publication 11 December 1995 Genetics, Faculty of of Stellenbosch,

\section{A novel deletion at codon 441 of the APC gene associated with ophthalmic lesions (CHRPE) in a South African family}

Johanna J Grobbelaar, Ari Ziskind, Greetje de Jong, C J Joubert Oosthuizen, Maritha J Kotze

\begin{abstract}
A novel mutation at codon 441 in exon 10 of the adenomatous polyposis coli (APC) gene was identified in a South African family of mixed ancestry, using a convenient, non-radioactive, heteroduplexSSCP screening assay. This single thymidine deletion after nucleotide position 1322 creates a frameshift resulting in a downstream stop codon at amino acid residue 453 of the APC gene. Genotypes of nine family members were subsequently
\end{abstract}
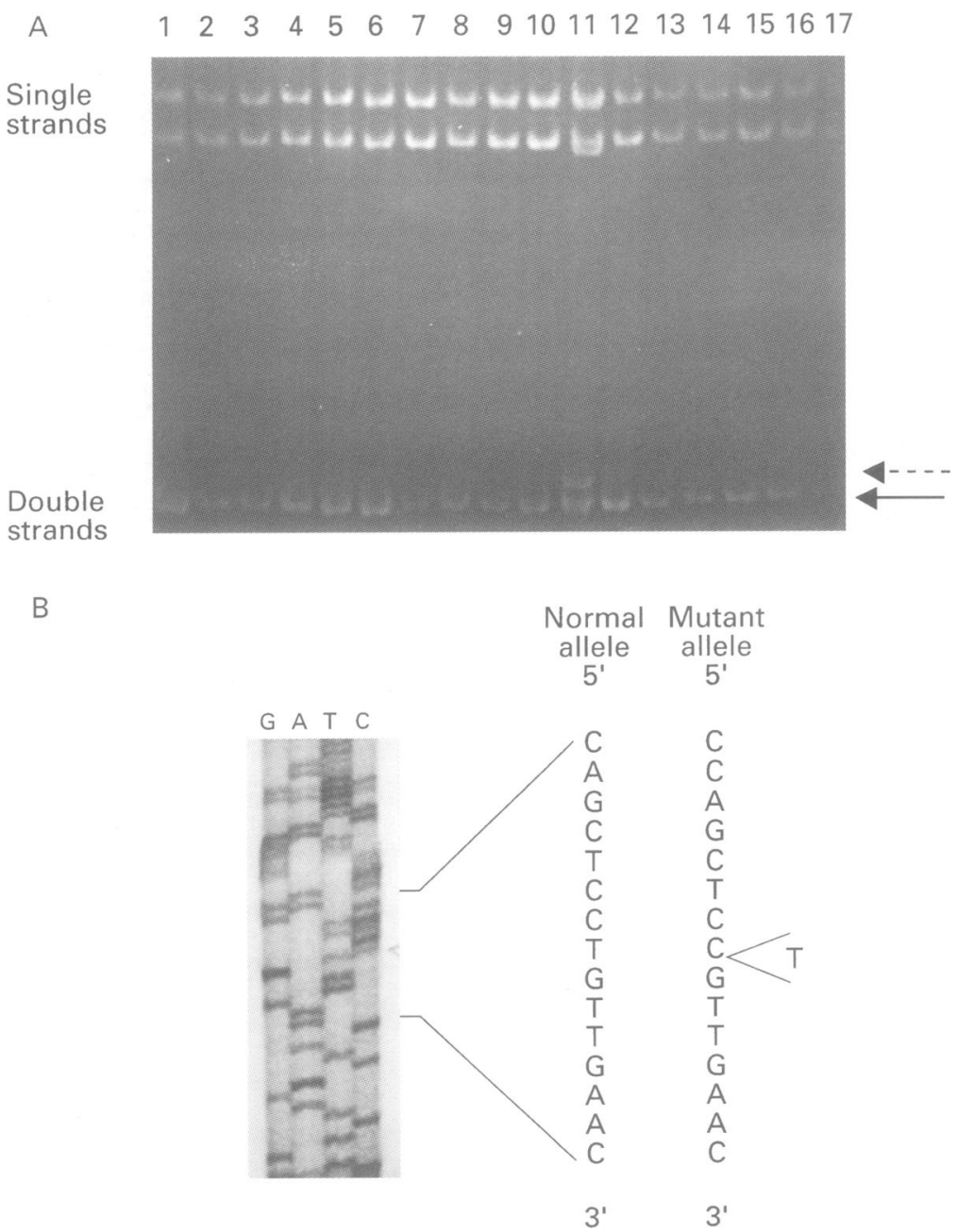

Figure 1 Identification of a 1 bp deletion at codon 441 of the APC gene. (A) Heteroduplex-SSCP analysis of PCR products from 17 FAP patients in a $10 \%(2 \cdot 5 \%$ cross linked) polyacrylamide gel supplemented with $7.5 \%$ urea and stained with ethidium cross linked) polyacrylamide gel supplemented with 11 the PCR amplified DNA of one index patient shows abberant single (upper bands) and double stranded (lower bands) conformational polymorphisms.

Homoduplex (solid arrow) and heteroduplex (broken arrow) bands observed in the double stranded DNA are indicated on the right side of the gel. (B) Direct DNA sequencing of the patient showing the aberrant bands in lane 11. correlated with the presence or absence of congenital hypertrophy of the retinal pigment epithelium (CHRPE), since expression of this common extracolonic manifestation of FAP is largely determined by the length of the truncated protein. CHRPE was absent in the five unaffected family members analysed, while four mutation positive subjects showed these ophthalmic lesions. Correlation between the molecular analysis and ophthalmic examinations, performed without knowledge of clinical and genetic status respectively, provided additional evidence in favour of the view that the range of phenotypic expression in FAP may result from different allelic manifestations of APC mutations.

(f Med Genet 1996;33:384-386)

Key words: familial adenomatous polyposis coli; ophthalmic lesions (CHRPE); frameshift mutation.

Mutations in the adenomatous polyposis coli (APC) gene cause the autosomal dominant disease familial adenomatous polyposis (FAP).$^{1-4}$ Congenital hypertrophy of the retinal pigment epithelium (CHRPE) is clinically the most common and most reliable extracolonic manifestation of FAP, ${ }^{56}$ and has been shown to be present in patients with mutations in codons 457-1387 of the APC gene. ${ }^{78}$ Patients with mutations in codons 136-302 and beyond codon 1444 regularly do not develop CHRPE, while patients with mutations in codons 413 437 have an intermediate CHRPE score. ${ }^{7-9}$ The expression of ophthalmic lesions can thus potentially be used to restrict mutation screening in a subset of clinically diagnosed FAP patients to a specific region of the APC gene. In this study we identified a novel mutation at codon 441 in exon 10 of the APC gene and showed that this allelic site is associated with the presence of CHRPE.

\section{Methods}

Genomic DNA was extracted from 17 apparently unrelated South African FAP patients, ${ }^{10}$ PCR amplified according to Miyoshi et al, ${ }^{11}$ and screened for mutations in exon 10 (codon 439-470) of the APC gene by combined heteroduplex-SSCP analysis, as described by Kotze et al. ${ }^{12}$ Segregation analysis was subsequently performed using genomic DNA ex- 


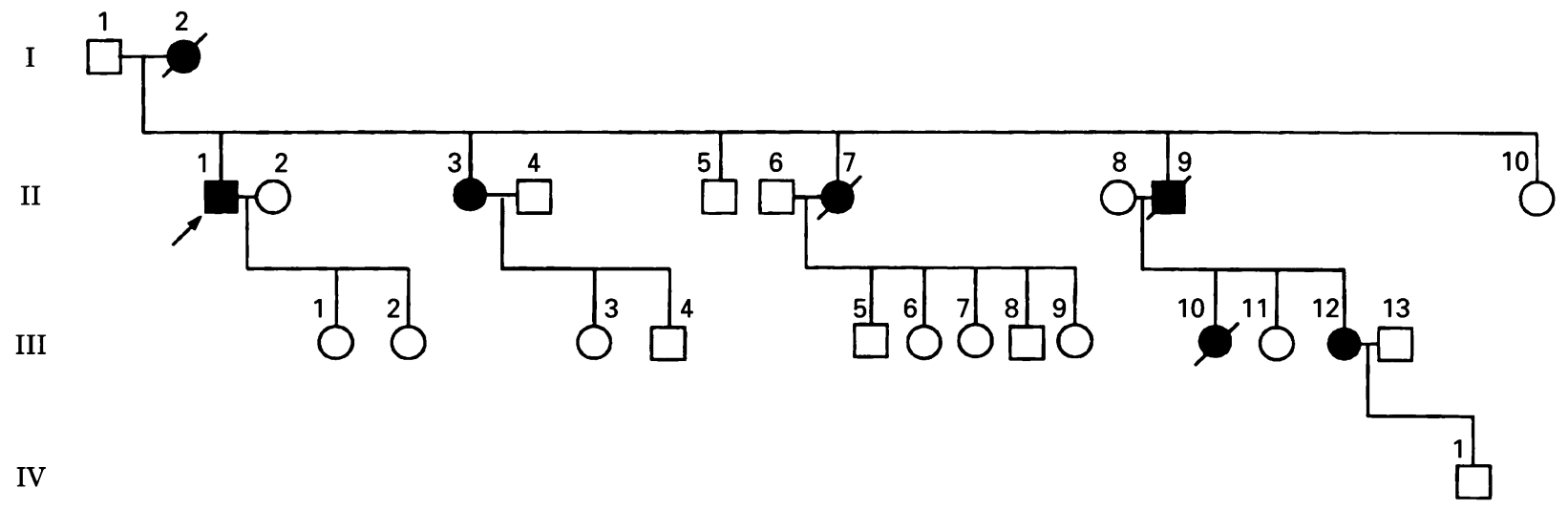

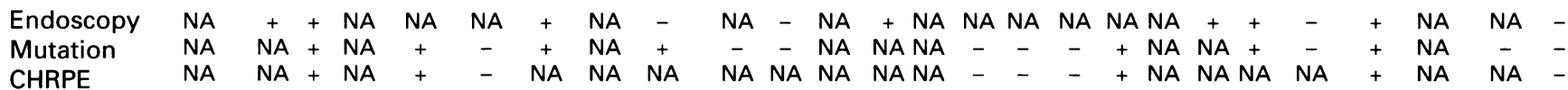

Figure 2 Pedigree of the index patient (marked by an arrow) with the 1 bp deletion. Dark shaded symbols represent clinically diagnosed FAP patients. Subjects who underwent colectomies, DNA screening, and indirect ophthalmoscopy are indicated with + for presence and - for absence of the respective parameters. $N A=$ not analysed; $C H R P E=$ congenital hypertrophy of the retinal pigment epithelium.

Ophthalmic lesions in CHRPE positive subjects. Large lesions were bigger than half optic disc diameter (DD), small lesions were smaller than one half $D D$

\begin{tabular}{ll}
\hline & Patients $(n=4)$ \\
\hline At least 1 CHRPE & 1 \\
$\geq$ 4 CHRPE & 2 \\
Large lesions present & 1 \\
Small lesions only & \\
\hline
\end{tabular}

tracted from 15 members of one relatively large family (21 members). Direct DNA sequence analysis was performed by using a PCR preparation kit and T7 DNA Polymerase (Pharmacia Biotechnology), as previously described. ${ }^{13}$ Indirect ophthalmoscopy was performed in the index case and eight of his relatives following pupil dilatation. The criteria used to differentiate between a CHRPE positive and CHRPE negative status are presented in detail elsewhere.

\section{Results}

In one of the 17 FAP patients screened for mutations in exon 10 of the APC gene (fig 1A), a single thymidine deletion was identified after nucleotide position 1322 at codon 441 (fig 1B). Mutation screening of PCR amplified DNA obtained from 15 family members of the index patient (II 1 ) showed that six additional subjects inherited the single nucleotide deletion (fig 2). Indirect ophthalmoscopy performed on the index patient and eight family members showed that four subjects had CHRPE lesions (table). To date, the mutation/CHRPE positive subjects III 1 ( 10 years) and III 9 ( 6 years) have not shown any clinical symptoms. The five mutation negative subjects (II 10 , III $\cdot 2$, III.6, III $\cdot 7$, and III·8) did not present with CHRPE lesions.

\section{Discussion}

A novel single nucleotide deletion (T) at codon 441 of the APC gene was identified in a South African family. This frameshift mutation cre- ates a downstream stop codon at a position corresponding to amino acid residue 453 . The truncated APC protein, predicted to result from this alteration, probably underlies the FAP phenotype in the index patient and his affected family members. Cosegregation of the mutation with the FAP phenotype was shown in three generations. The previously described relationship between the site of APC mutation and phenotypic expression of CHRPE, ${ }^{7-10}$ the most common extracolonic manifestation of FAP, ${ }^{56}$ was subsequently studied in the South African family. As expected, all the mutation positive subjects identified in this study, who could be traced and were subjected to ophthalmic examinations, showed the CHRPE phenotype. Those that did not inherit the deleted allele were CHRPE negative, thus confirming the intrafamilial CHRPE correlation.

The majority of FAP related mutations identified world wide, including all the mutations identified to date in South Africa, ${ }^{13} 14$ are frameshifts resulting in truncated proteins. Consistent findings that the expression of CHRPE is largely determined by the length of the mutant APC protein product, therefore, have important diagnostic implications with respect to facilitating the detection of FAP related mutations. The screening of the entire coding region of the APC gene for mutation detection in order to provide diagnostic reliability can now be narrowed down to specific gene regions in cases examined ophthalmoscopically.

We are grateful to the FAP patients and their families. This work was supported by the National Cancer Association of South Africa, the University of Stellenbosch, and the Administration, Western Cape.

1 Kinzler KW, Nilbert NC, Su LK, et al. Identification of FAP locus genes from chromosome 5q21. Science 1991; 253:661-5.

2 Groden J, Thliveris A, Samowitz W, et al. Identification and . gene. Cell 1991;66:689-700.

3 Joslyn G, Carlson M, Thliveris A, et al. Identification of deletion mutations and three new genes at the familial deletion mutations and three new gen

4 Nishisho I, Nakamura Y, Miyoshi Y, et al. Mutations of chromosome 5q21 genes in FAP and colorectal cancer patients. Science 1991;253:665-9. 
5 Lewis RA, Crowder WE, Eierman LA, Nussbaum RL, Ferrell RE. The Gardner syndrome: significance of ocular features. Ophthalmology 1984;91:916-25.

6 Morton DG, Gibson J, Macdonald F, et al. Role of congenital hypertrophy of the retinal pigment epithelium in the prehypertrophy of the retinal pigment epithelium in the pre-
dictive diagnosis of familial adenomatous polyposis. $\mathrm{Br} \mathcal{F}$ dictive diagnosis of famil
Surg 1992;79:689-93.

7 Olswhwang S, Tiret A, Laurent-Puig P, Muleris M, Parc $R$, Thomas G. Restriction of ocular fundus lesions to a specific subgroup of APC mutations in adenomatous polyposis coli patients. Cell 1993;75:959-68.

8 Wallis YL, Macdonald F, Hultén M, et al. Genotype-phenotype correlation of constitutional APC gene mutation and CHRPE expression in familial adenomatous polyposis. Hum Genet 1994;94:543-8.

9 Caspari R, Olschwang S, Friedl W, et al. Familial adenomatous polyposis: desmoid tumors and lack of oph(CHPE) associated with APC mutations beyond codon 1444. Hum Mol Genet 1995;4:337-40.
10 Grobbelaar JJ, Oosthuizen CJJ, Madden MV, Bailey SE, Retief AE, Kotze MJ. The use of DNA markers in the pre-clinical diagnosis of familial adenomatous polyposis

11 Miyoshi Y, Ando H, Nagase H, et al. Germ-line mutations Miyoshi Y, Ando $\mathrm{H}$, Nagase $\mathrm{H}$, et al. Germ-line mutations
of the APC gene in 53 familial adenomatous polyposis of the APC gene in 53 familial adenomatous poly
patients. Proc Natl Acad Sci USA 1992;89:4452-6.

patients. Proc Natl Acad Sci USA 1992;89:4452-6.
12 Kotze MJ, Theart L, Callis M, Peeters AV, Thiart R, Langenhoven E. Nonradioactive multiplex PCR screening strategy for the simultaneous detection of multiple low density lipoprotein receptor gene mutations. PCR Meth Appl 1995; 4:352-6.

13 Grobbelaar JJ, Oosthuizen CJJ, Kotze MJ. Screening South African familial adenomatous polyposis families for the five-nucleotide deletion at codon 1309 of the APC gene. Mol Cell Probes 1995;9:49-52.

14 Kotze MJ, Grobbelaar JJ, Madden MV. Identification of a novel single base insertion in the adenomatous polyposis coli gene. Hum Mutat 1996;7:68-9. 